\title{
Cómo avanzar en la lucha por la libertad e igualdad de la mujer: propuestas legales frente a la cosificación, hipersexualización y pornificación de la sociedad*
}

\author{
How to progress in the fight for women's freedom \\ and gender equality: legal proposals in face \\ of objectification, hipersexualization and pornification \\ of contemporary society
}

\author{
Carlos Padrós Reig** \\ Catedrático (Acred.) de Derecho Administrativo \\ Universidad Autónoma de Barcelona \\ Ex-Letrado del Tribunal Constitucional de España \\ ORCID ID: 0000-0003-0002-9412
}

Recibido: $11 / 2 / 2021$

Aceptado: $15 / 4 / 2021$

doi: https://doi.org/10.20318/femeris.2021.6139

\begin{abstract}
Resumen. La lucha por la igualdad y la libertad de la mujer a través de la represión de los delitos de género y las agresiones sexuales arroja un resultado decepcionante. La cuestión lejos de presentar una mejora, parece empeorar. Ello puede deberse a la irrupción en nuestras sociedades de los fenómenos de la hipersexualización y la cosificación de la mujer. Pero también a la creciente disponibilidad absoluta de contenidos pornográficos cada vez más violentos y vejatorios contra las mujeres. Frente a ello, el enfoque legal basado en la represión de las conductas debe acompañarse de medidas preventivas o anticipatorias: un mejor control de ciertos contenidos; un sistema efectivo de limitación de acceso; una aplicación de las figuras penales de la inducción o la apología respecto a la difusión de contenidos ilícitos; la aplicación del tipo específico del delito de odio por razón de género; una extensión de la responsabilidad de quienes alojen estos contenidos en la red.

Palabras clave: hipersexualización; cosificación; pornografía; contenidos humillantes o degradantes contra la mujer; control de acceso a Internet.

Abstract. The fight for women's equality and freedom through the repression of genderbased crimes and sexual assaults offers a discouraging result. Far from experiencing any improvement, the issue seems to be worsening. This may be due to the irruption in our contemporary societies of the phenomena of hypersexualization and objectification of women. But it may also be due to the increasing availability of pornographic contents that are more violent and vexatious against women. In the face of this, the legal approach based on the prosecution
\end{abstract}

\footnotetext{
*Texto enviado el 11 de febrero de 2021. Agradezco sinceramente a mis colegas Rafael Rebollo Vargas y Joaquín Rodríguez Álvarez que hayan dedicado parte de su valioso tiempo a leer una versión preliminar de este trabajo. Algunos de los errores que puedan persistir se deben a mi empecinamiento en no hacer caso a sus sabios consejos.

***carlos.padros@uab.cat
} 
of criminal conducts must be accompanied by preventive or anticipatory measures: better control of certain web content; an effective system for limiting Internet access; application of the legal tools of inducement or apology of crime for the dissemination of illegal content; application of the specific type of gender-based hate crime; an extension of the liability of those who host such content on the network.

Keywords: sexualization; cosification; pornography; internet access limits; humiliating or degrading internet contents against women.

\section{Introducción}

Se hace público en los primeros meses de andadura de la XIV legislatura de las Cortes españolas, el Anteproyecto de Ley Orgánica de Garantía Integral de la Libertad Sexual de la mujer ${ }^{1}$. El énfasis de los debates iniciales parece centrarse en la cuestión del consentimiento expreso ("solo sí es sí") y en la eliminación de las categorías jurídicas que distinguirían -según la gravedad- el abuso sexual de la agresión sexual. Todo ataque no consentido a una mujer constituirá una agresión sexual, con independencia de la existencia o menos de violencia o intimidación.

Cualquier avance en la protección de esa libertad sexual debe ser celebrado ${ }^{2}$. Pero la hipótesis que nos planteamos en estas páginas es que la Ley no solucionará -porque no lo aborda- ${ }^{3}$ un problema de mayor profundidad y calado como es la progresiva sexualización de la mujer que la degrada en su posición como plena persona en sociedad para convertirla en un bien comercial. Pretendemos argumentar que las medidas legales de protección deben empezar por abordar las causas de las agresiones. No bastará con mejorar los instrumentos normativos de la represión de las agresiones sexuales, al igual que no basta para atajar la insufrible violencia de género con aumentar el castigo a los agresores.

Como ilustración de lo anterior, podemos analizar la estadística INE sobre muertes de mujeres a causa de la violencia de género en el período que comprende 1999-20194.

Tabla 1. Mujeres muertas a causa de violencia de género. España.

\begin{tabular}{|c|c|c|c|c|c|c|c|c|c|c|}
\hline $\mathbf{1 9 9 9}$ & $\mathbf{2 0 0 0}$ & $\mathbf{2 0 0 1}$ & $\mathbf{2 0 0 2}$ & $\mathbf{2 0 0 3}$ & $\mathbf{2 0 0 4}$ & $\mathbf{2 0 0 5}$ & $\mathbf{2 0 0 6}$ & $\mathbf{2 0 0 7}$ & $\mathbf{2 0 0 8}$ & $\mathbf{2 0 0 9}$ \\
\hline 54 & 63 & 50 & 54 & 71 & 72 & 57 & 69 & 71 & 76 & 56 \\
\hline $\mathbf{2 0 1 0}$ & $\mathbf{2 0 1 1}$ & $\mathbf{2 0 1 2}$ & $\mathbf{2 0 1 3}$ & $\mathbf{2 0 1 4}$ & $\mathbf{2 0 1 5}$ & $\mathbf{2 0 1 6}$ & $\mathbf{2 0 1 7}$ & $\mathbf{2 0 1 8}$ & $\mathbf{2 0 1 9}$ & prom. \\
\hline 73 & 61 & 52 & 54 & 55 & 60 & 49 & 50 & 51 & 55 & 56 \\
\hline
\end{tabular}

Fuente: Elaboración propia. Datos 1995-2005: Instituto de la Mujer. Datos 2006-2019: Delegación del Gobierno para la violencia de género.

1 Texto disponible en https://www.igualdad.gob.es/normativa/normativa-en-tramitacion/Documents/APLOGILSV2.pdf

${ }^{2}$ Ello no obsta para la manifestación de fundadas deficiencias técnicas que puede presentar el texto. Cfr. Gimbernat, E. (25 de abril de 2020). "Solo sí es sí". El Mundo. Disponible en https://www.iustel.com/diario_del_derecho/noticia. asp?ref_iustel=1197551

${ }^{3}$ Más que en una tímida referencia en el articulo 10.1 relativo a las medidas de prevención en el ámbito digital y de la comunicación.

${ }^{4}$ Se incluyen aquellos casos en los que el agresor es el cónyuge, excónyuge, compañero sentimental, excompañero sentimental, novio o exnovio. Fuente:1999-2005: Instituto de la Mujer a partir de noticias de prensa y de datos del Ministerio del Interior. A partir de 2006 datos de la Delegación del Gobierno para la Violencia de Género. Disponible en https://ine.es/jaxi/Datos.htm?path=/t00/mujeres_hombres/tablas_1/10/\&file=v02001.px\#!tabs-tabla 
Las cifras constatan que, pese a los esfuerzos, la cifra se mantiene relativamente estable en torno al promedio (56 mujeres asesinadas/año).

Lo anterior se puede también cruzar con los hitos normativos en materia de protección de la mujer y lucha contra la violencia de género ${ }^{5}$ :

- 2002. Se crea el Observatorio contra la Violencia Doméstica. El Gobierno y el Consejo General del Poder Judicial (CGPJ) firmaron el 26 de septiembre de 2002 el convenio de creación del "Observatorio contra la Violencia Doméstica” para el seguimiento exhaustivo de las sentencias sobre malos tratos, contra los que el gobierno quería ser "inflexible".

- 2003. Los grupos parlamentarios de las Cortes llegan a un acuerdo para aprobar una nueva herramienta en la lucha contra la violencia y nacen así las órdenes de protección para las mujeres que sufran violencia de género.

- 2004. Las Cortes Generales aprueban por unanimidad la ley integral contra la violencia de género. Ley Orgánica 1/2004, de 28 de diciembre, de Medidas de Protección Integral contra la Violencia de Género ${ }^{6}$.

- 2005. El 29 de junio de 2005 entraron en funcionamiento como órganos especializados, los juzgados de violencia sobre la mujer y las secciones especializadas en el seno de las Audiencias Provinciales de toda España, dando cumplimiento así a una de las previsiones de la Ley Orgánica $1 / 2004 .^{7}$

- 2007. El Congreso aprueba la Ley Orgánica 3/2007, de 22 de marzo, para la igualdad efectiva de mujeres y hombres.

- 2007. Entra en funcionamiento el 016 , un número contra los malos tratos contra las mujeres.

- 2017. En septiembre, el Congreso de los Diputados aprueba el primer Pacto de Estado contra la Violencia de Género ${ }^{8}$. Se trata de un plan que contiene 200 medidas y una dotación presupuestaria específica para hacer frente a las agresiones machistas.

Si correlacionamos los hitos normativos con las cifras, podemos concluir que, tal vez excepto para 2005 (año posterior a la aprobación de la Ley Orgánica de Protección Integral, donde el número de víctimas pasa a ser de 72 en 2004 a 56 en 2005 arrojando una disminución de 16 víctimas lo que supone cerca de un 22\%), el resto de años de la serie (con matizaciones para 2009, y 2011-2012) las medidas normativas presentarían un impacto modesto o estadísticamente poco relevante.

\footnotetext{
${ }^{5}$ https://elpais.com/especiales/violencia-de-genero/hitos-y-logros/

${ }^{6}$ BOE no 313 de 29 de diciembre de 2004. Disponible en versión consolidada en https://www.boe.es/buscar/act. php?id=BOE-A-2004-21760.

${ }^{7}$ La aplicación judicial de la LO 1/2004 puede consultarse en el documento “Quince años de la Ley Orgánica 1/2004, de 28 de diciembre, de Medidas de Protección Integral contra la Violencia de Género en los órganos judiciales" Boletín de Información Estadística CGPJ no 80, 2021. Disponible en https://www.poderjudicial.es/cgpj/es/Temas/EstadisticaJudicial/Estudios-e-Informes/Violencia-sobre-la-Mujer/

${ }^{8}$ Texto disponible en https://violenciagenero.igualdad.gob.es/pactoEstado/home.htm. Desarrollado por Real Decreto-ley 9/2018, de 3 de agosto, de medidas urgentes para el desarrollo del Pacto de Estado contra la violencia de género.
} 
También pueden cruzarse los datos estadísticos con la cadencia de las legislaturas parlamentarias y gobiernos. Con ello podríamos refutar la hipótesis que no se trata de un problema normativo sino de medidas administrativas (política pública) . Así, grosso modo, el período comprende entre la VII y la XIV legislaturas de las Cortes Generales. Y ello da lugar a una alternancia de gobiernos populares y socialistas que pueden expresarse en los siguientes degradados de gris:

Tabla 2. Mujeres muertas a causa de violencia de género, con expresión del partido de gobierno. España.

\begin{tabular}{|c|c|c|c|c|c|c|c|c|c|c|}
\hline $\mathbf{1 9 9 9}$ & $\mathbf{2 0 0 0}$ & $\mathbf{2 0 0 1}$ & $\mathbf{2 0 0 2}$ & $\mathbf{2 0 0 3}$ & $\mathbf{2 0 0 4}$ & $\mathbf{2 0 0 5}$ & $\mathbf{2 0 0 6}$ & $\mathbf{2 0 0 7}$ & $\mathbf{2 0 0 8}$ & $\mathbf{2 0 0 9}$ \\
\hline 54 & 63 & 50 & 54 & 71 & 72 & 57 & 69 & 71 & 76 & 56 \\
\hline $\mathbf{2 0 1 0}$ & $\mathbf{2 0 1 1}$ & $\mathbf{2 0 1 2}$ & $\mathbf{2 0 1 3}$ & $\mathbf{2 0 1 4}$ & $\mathbf{2 0 1 5}$ & $\mathbf{2 0 1 6}$ & $\mathbf{2 0 1 7}$ & $\mathbf{2 0 1 8}$ & $\mathbf{2 0 1 9}$ & prom. \\
\hline 73 & 61 & 52 & 54 & 55 & 60 & 49 & 50 & 51 & 55 & 56 \\
\hline
\end{tabular}

Fuente: Elaboración propia. Datos 1995-2005: Instituto de la Mujer. Datos 2006-2019: Delegación del Gobierno para la violencia de género.

El final del segundo mandato del presidente Aznar (2003), deja un número sustancialmente más elevado que los años anteriores. El primer gobierno Rodríguez Zapatero revierte la situación (2005) y vuelve a datos más homogéneos con el inicio de la serie. Pero el segundo gobierno socialista deja la peor cifra absoluta de toda la serie (2008). La media de mujeres asesinadas en períodos donde el ejecutivo lo ostenta el partido popular es de 56,2. La de que corresponde al partido socialista es de 62,8. De los diez años de gobiernos populares, dos han arrojado cifras superiores al promedio de la serie (56). De los once años de gobiernos socialistas, siete han contabilizado más muertes que la media (todos ellos de los ejecutivos del presidente Rodríguez Zapatero).

Por todo ello, la cuestión no parce ser de normativa (poca o mucha) ni de políticas (gobiernos más implicados o menos). ${ }^{9}$

El problema -parece fuera de duda- no se soluciona con más normas. La cuestión no es simple ni podemos recurrir al "normativismo mágico" según el cual, la sola aprobación de las normas transforma la terrible realidad. Hacen falta políticas públicas, formación especializada, educación, pedagogía colectiva, sensibilidad de los operadores jurídicos, y un compromiso institucional generalizado, lo que incluye recursos humanos y económicos.

Pese a lo anterior, lo cierto es que no termina de comprenderse porqué el ordenamiento jurídico no utiliza algunos medios que tendría a su alcance para tratar la cuestión. La pregunta que nos hacemos -y que motiva las páginas que sigue- es si el ordenamiento legal español podría hacer algo más para corregir una patología social que parece impropia de una sociedad, no ya igualitaria, sino mínimamente decente. Y tal vez el Derecho debería actuar en un momento anterior a la producción de la violencia, como una herramienta no solo reactiva, sino anticipatoria.

\footnotetext{
${ }^{9}$ Quedaría un tercer elemento de contraste -además de normas y gobiernos- como son las dotaciones presupuestarias dedicadas a las políticas públicas de protección contra la violencia en cada uno de los años, pero esta metodología e hipótesis, interesante y crucial como puede ser, se escapa por ahora del objetivo de esta investigación.
} 
El anterior análisis cuantitativo de los casos de violencia de género puede trasladarse igualmente a las estadísticas sobre delitos contra la libertad sexual, cuyo sesgo de género es también indiscutible ${ }^{10}$. Los datos que ofrece el Consejo General del Poder Judicial son limitados pero indican unos porcentajes alarmantes. Así, en el registro de condenados por delitos sexuales ${ }^{11}$ se computan 3.296 en 2019 (3.216 cometidos por hombres (97,5\%) y 80 por mujeres (2,5\%)); 2.917 en 2018 (2.820 cometidos por hombres (96,6\%) y 97 por mujeres $(3,4 \%)$ ) y 2.764 en 2017 (2.666 cometidos por hombres $(96,4 \%)$ y 98 por mujeres $(3,6 \%)$ ). La serie estadística disponible es muy corta pero indica, además del sesgo, un preocupante crecimiento de las condenas (6,3\% promedio anual). Y la cuestión no parece que se deba a una mayor efectividad del sistema judicial en la persecución sino a un incremento de los hechos delictivos. Así, si se desprende de comparar lo anterior con los datos policiales que ofrece el I Informe sobre delitos contra la libertad e indemnidad sexual en España publicado por la Secretaría de Estado de Seguridad (Ministerio de Interior) en $2017^{12}$, resulta que los hechos esclarecidos registrados son:

Tabla 3. Delitos contra la libertad e indemnidad sexual. Hechos esclarecidos registrados.

\begin{tabular}{|l|l|}
\hline $\mathbf{2 0 1 2}$ & 6.698 \\
\hline $\mathbf{2 0 1 3}$ & 6.766 \\
\hline $\mathbf{2 0 1 4}$ & 7.088 \\
\hline $\mathbf{2 0 1 5}$ & 7.500 \\
\hline $\mathbf{2 0 1 6}$ & 8.381 \\
\hline $\mathbf{2 0 1 7}$ & 8.894 \\
\hline
\end{tabular}

Fuente: Informe sobre delitos contra la libertad e indemnidad sexual en España. Secretaría de Estado de Seguridad. Ministerio de Interior. 2017.

De nuevo, el incremento anual promedio es del 5,3\%.

En definitiva, pese a los esfuerzos normativos, la cuestión está muy lejos de mejorar. Nuestra hipótesis de investigación se centra pues en demostrar las limitaciones de la sola

10 "Debería considerarse la violencia sexual como una forma de violencia de género, teniendo en cuenta que ésta afecta a las mujeres de forma desproporcionada. Dicha asimilación permitiría brindar mayor protección a las supervivientes y garantizar que sus actos sean tratados con perspectiva de género, es decir, apreciando el contexto de violencia sistémica y desequilibrio de las relaciones de poder entre géneros." Ubieto Olivan, A. (2018). Cuerda Arnau, M.L. (2010).

${ }^{11}$ Consejo General del Poder Judicial. Estadística Judicial. Delincuentes Sexuales (explotación estadística del Registro Central de Delincuentes Sexuales) https://www.poderjudicial.es/cgpj/es/Temas/Estadistica-Judicial/Estadistica-portemas/Datos-penales--civiles-y-laborales/Delitos-y-condenas/Delincuentes-Sexuales--explotacion-estadistica-del-Registro-Central-de-Delincuentes-Sexuales-/

${ }^{12}$ Secretaría del Estado de Seguridad. Ministerio del Interior. I Informe sobre delitos contra la libertad e indemnidad sexual en España (2017) http://www.interior.gob.es/documents/10180/0/Informe+delitos+contra+la+libertad+e+indemn idad+sexual+2017.pdf/da546c6c-36c5-4854-864b-a133f31b4dde Comprende la suma de los siguientes tipos delictivos: abuso sexual; agresión sexual; pornografía de menores; exhibicionismo; corrupción menores/incapacitados; contacto por medio de tecnología con menores de 16 años; acoso sexual; delitos relativos prostitución; provocación sexual. Según el art. 36 del Convenio de Estambul, debe entenderse por "violencia sexual, incluida la violación: la penetración vaginal, anal u oral no consentida, con carácter sexual, del cuerpo de otra persona con cualquier parte del cuerpo o con un objeto; los demás actos de carácter sexual no consentidos sobre otra persona; el hecho de obligar a otra persona a prestarse a actos de carácter sexual no consentidos con un tercero." Igualmente el precepto establece en su apartado segundo que: "El consentimiento debe prestarse voluntariamente como manifestación del libre arbitrio de la persona considerado en el contexto de las condiciones circundantes." Convenio del Consejo de Europa sobre prevención y lucha contra la violencia contra las mujeres y la violencia doméstica. Hecho en Estambul el 11 de mayo de 2011. Texto disponible en https://rm.coe.int/1846543 
utilización de la reforma normativa, a la vez que se propone una intervención temprana del Derecho como herramienta de prevención general.

Para todo ello, abordaremos en primer lugar una descripción de los fenómenos que encabezan el título: la cosificación del cuerpo femenino; la hipersexualización de las relaciones humanas y, finalmente, la ubicua presencia de la pornografía en los contenidos de las redes. En segundo lugar, trataremos de describir algunos de los instrumentos de los que dispone el ordenamiento jurídico para proteger el que, a nuestro juicio, es el bien jurídico de mayor importancia: la libertad sexual de la mujer y su igualdad respecto del hombre. Se trata de actuar preventivamente o de, como mínimo, evitar normalizar aquello que lisa y llanamente constituye un atentado contra la dignidad de las mujeres y por ello abre la puerta a comportamientos ilegales y gravemente dañinos. Solo así se consigue explicar que una generación de jóvenes siga exhibiendo razonamientos a todas luces inaceptables en las relaciones de pareja.

\section{Los fenómenos}

2.1. Cosificación. La teoría feminista ${ }^{13}$ describe la cosificación sexual de la mujer adulta como un proceso de reducción de la persona a un objeto (cuerpo) sexual donde la belleza física prevalece sobre la personalidad y la existencia como individuo. La cosificación tiene lugar a menudo en las representaciones de mujeres en la publicidad comercial y en medios de comunicación donde se ignora la capacidad intelectual o profesional de la mujer para centrarse única y exclusivamente en su aspecto físico.

Viene inmediatamente a la mente el antiguo anuncio de perfume de los años 80 "Jacqs" donde la huella del hombre era la marca de un neumático sobre el cuerpo femenino. 0 el más reciente de Dolce \& Gabana de 2007 donde un hombre sujeta por las muñecas a una mujer tumbada en el suelo mientras otros cuatro varones se recrean mirando la escena en lo que podría evocar un acto sexual inconsentido. El Gobierno español al reputar que la fotografía podía representar una violación, pidió a los diseñadores italianos que retiraran los anuncios, cosa que éstos hicieron no sin antes acusar a las autoridades españolas de atrasadas al no entender la expresión artística de la marca ${ }^{14}$.

La cosificación es una construcción claramente machista y que denigra la persona (mujer) y la reduce a un instrumento de placer de otra (hombre). Esta cosificación sexual -aunque no es exclusivamente unidireccional- juega un papel importante en la desigualdad de género. Además de lo anterior, la presión social en un contexto de cosificación de la mujer adulta puede llegar a desembocar en la autocosificación: "La autocosificación se

\footnotetext{
${ }^{13}$ Bartky, S. L. (1990) Femininity and Domination: Studies in the Phenomenology of Oppression. Routledge; Barry, K. (1994). Female Sexual Slavery. NYU Press; Puleo, Alicia H. (2015). Ese oscuro objeto del deseo: cuerpo y violencia. Investigaciones Feministas, 6, 122-138.

${ }^{14}$ Cfr. el artículo de Silvestre, J. (29 de diciembre de 2015). Por qué los anuncios de perfume son tan sexuales. La Vanguardia. Disponible en https://www.lavanguardia.com/television/20151228/301080059093/anuncios-perfumecolonia-eroticos-porno-sexy.html; Alfaya Lamas, E. y Villaverde Solar, M.D. (2014) Deshumanizando a la mujer en la publicidad: un análisis de los nombres e imágenes de perfumes. Dossier Feminista 18. Disponible en https://dialnet. unirioja.es/servlet/articulo?codigo $=4941312$
} 
da cuando la mirada cosificadora se vuelve hacia una misma, de manera que las mujeres pasan a verse a sí mismas desde la perspectiva de un observador y ejercen una monitorización de sí mismas de forma crónica"15.

La cosificación resulta, además de odiosa, perniciosa para la propia mujer. De una parte, erosiona su autoestima al inducir en las mujeres imágenes negativas de sí mismas debido a la creencia de que su inteligencia y competencia no son ni reconocidas ni valoradas por la sociedad. Algunas adolescentes llegan incluso a sufrir miedo, vergüenza y asco durante la transición de la niñez a la feminidad porque sienten que se están convirtiendo en más visibles a la sociedad como objetos sexuales ${ }^{16}$. Según explica Isabel Valdés,

En 1998, Barbara Lee Fredrickson, profesora de psicología de la Universidad de Carolina del Norte pidió a unos estudiantes que se metieran en un vestuario, se pusieran un jersey o un bañador y que, durante diez minutos, completaran un examen matemático. Las chicas que lo hicieron en traje de baño tuvieron resultados significativamente peores que las que llevaban jersey. En ellos no hubo diferencia ${ }^{17}$.

2.2. Hipersexualización. No resulta ninguna novedad que vivimos en una sociedad que coloca las relaciones sexuales en un lugar muy destacado de la escala de valores colectivos. "El sexo repara, cura, une, relaja, prolonga la vida, previene el estrés, activa la producción de colágeno, protege nuestra salud cardiovascular, libera endorfinas que nos hacen sentir más felices"18. Sin embargo, esta especie de entronización de la sexualidad choca también con los mismos sesgos que antes. La sexualidad ha reproducido las relaciones de desigualdad entre hombres y mujeres.

Puede entenderse por hiperexualización la tendencia a reducir la mujer a sus atributos sexuales. Después de años de represión y pudor patriarcal, la mujer se siente libre de enseñar su cuerpo y reivindicar su sexualidad. El problema, sin embargo es dilucidar si esta sexualización de la mujer y de la sociedad en general supone realmente un signo de libertad para la mujer o una nueva modalidad de cosificación. "Si las amas de casa existían antes en un sistema que fomentaba la coerción, la represión de la sexualidad, el ocultamiento, ahora no se maneja tanto la prohibición como la incentivación e incitación a determinadas conductas, la producción de deseo. Se vende como empoderamiento aquello que sostiene y afirma la feminidad normativa más tradicional y patriarcal" ${ }^{\prime 2}$.

La hipersexualización convierte de nuevo a la mujer en un objeto (de deseo). Las mujeres son antes objetos disponibles sexualmente que personas en sociedad. El cuerpo

\footnotetext{
${ }^{15}$ Calogero, R. M., Tantleff-Dunn, S., y Thompson, J. K. (2011). Self-Objectification in women: Causes, consequences, and counteractions. American Psychological Association.

${ }^{16}$ Lee, J. (1994). Menarche and the (hetero)sexualization of the female body. Gender \& Society, 8(3), 343-362.

${ }^{17}$ Valdés, Isabel. (24 de noviembre de 2019). ¿Empodera la moda sexi? El País. https://elpais.com/elpais/2019/11/22/ ideas/1574452567_521860.html

${ }^{18}$ Benito, Marian (14 de enero de 2015). 365 días sin sexo. El Mundo, citado por De Miguel, Ana. (2019). Neolibrealismo sexual. El mito de la libre elección. Cátedra-Universitat de València. 12ª ed, 121-122.

${ }^{19}$ Valdés, Isabel. (24 de noviembre de 2019). ¿Empodera la moda sexi? El País. https://elpais.com/elpais/2019/11/22/ ideas/1574452567_521860.html
} 
sexualizado vende y se utiliza como reclamo de empoderamiento y libertad, cuando en realidad lo que hace es someter a la mujer a la mirada del otro (varón).

¿Es la hipersexualización realmente una elección libre de la mujer? La profesora Ana De Miguel (De Miguel, 2019) ha sintetizado la cuestión en su libro titulado Neoliberalismo Sexual ${ }^{20}$. El neoliberalismo se basa en la libre elección del individuo. La persona es libre para tomar sus decisiones sobre qué comprar o vender sin excesiva interferencia por parte del poder. Sin embargo, el paradigma neoliberal solo funciona con una premisa básica que raramente se da: los individuos deben tener una posición de partida igual y la información disponible para la elección debe ser óptima. En condiciones de desigualdad (hombre-mujer), el neoliberalismo sexual agrava las condiciones de discriminación.

La hipersexualización consigue la monetización de la sexualidad femenina. El valor de la mujer es la cantidad de deseo sexual que pueda producir. El cuerpo es nuevamente una mercancía, un instrumento para el éxito social o laboral. Y de este modo, una nueva imposición, ahora bajo el ropaje del libre consentimiento y el empoderamiento ${ }^{21}$.

En definitiva, el fenómeno descrito no cuestiona la revolución sexual ni las sexualidades diversas. No hay sexo ni relaciones sexuales normales o anormales. Lo que sucede es que el sexo, como forma de relación entre humanos, es un intercambio y por tanto susceptible de mercantilizarse. Quien más poder tenga ${ }^{22}$, más podrá imponer una determina concepción de la mujer y el sexo. Y ello no es una cuestión de moralidad puritana, es una cuestión de desigualdad de partida.

2.3. Pornificación. Los contenidos pornográficos constituyen el gran negocio de Internet. Los datos, se mire la fuente que se mire, son apabullantes.

En el año 2008, la revista Forbes calculaba que 30 millones de personas estaban diariamente conectadas a la red en busca de imágenes de sexo explícito en alguna de las 260 millones de páginas web que ofrecen pornografía. En todo el mundo, el negocio registra beneficios de unos 60.000 millones de dólares anuales. Se calcula que en Estados Unidos, los videos porno generan más dinero que los ingresos combinados de las franquicias de fútbol profesional, béisbol y baloncesto ${ }^{23}$.

Una de las derivas de la pornocultura, (Iglesias y Zein, 2018), es que el porno nos pide más:

contemplarlo produce una especie de inundación de dopamina en nuestro cerebro, que con tan altas dosis de hormonas del bienestar, reduce su actividad en los centros de recompensa, el aprendizaje y la memoria. Al producirse y agotarse esta descarga, el organismo necesita producirla nuevamente, por lo que las descargas hormonales promueven la

\footnotetext{
${ }^{20}$ De Miguel, Ana. (2019).

${ }^{21}$ cfr. Fernández Estrada, María. (2011).

${ }^{22}$ La pornografía como expresión de poder se analiza en Cobo, R. (2020).

${ }^{23}$ Iglesias, A. y Zein, M. (2018),45.
} 
repetición de las conductas. No todas las personas que consumen son adictas, por supuesto, pero la sociedad en la que nos movemos, sí ${ }^{24}$.

No defendemos aquí una posición moral que cuestione los contenidos pornográficos susceptibles de provocar excitación sexual. No hay nada de moralista o puritano en nuestro análisis. Los contenidos pornográficos existen y su gran disponibilidad de acceso a través de un dispositivo móvil hace inviable su completa represión. Pero la pornificación es especialmente perniciosa en dos aspectos: es el canal de educación sexual de los niños y niñas y de los adolescentes y; algunos (muchos) de sus contenidos denigran profundamente la mujer.

De nuevo, como se explica (De Miguel, 2019)

La pornografía se ha hecho omnipresente a través de internet. La sumisión frente a la invasión de nuestro espacio es casi total, ni siquiera hay oposición a que los menores puedan acceder a los contenidos porno. Es posible encontrar menús con todo tipo de chicas a la carta. (...) Uno de los rasgos de esta expansión sin controles es la de que cada día salen imágenes más violentas y exageradas. (...) A las jóvenes están empezando a parecerles normales, por frecuentes, visiones muy vejatorias y humillantes de otras mujeres y de lo que se puede hacer con ellas ${ }^{25}$.

Una reciente contribución de académicos de la Universitat de les Illes Balears, correlaciona la pornificación (mayor acceso y presencia del porno entre los jóvenes), con unos mayores niveles de violencia y de consumo de prostitución ${ }^{26}$.

La familiariedad con prácticas sexuales extremas es muy común, alterando la percepción sobre su aceptabilidad. La nueva pornografía muestra e impone un modelo de relación desigual, en el que la mujer es reducida a objeto sexual disponible para el hombre. No solo se muestran situaciones de alto riesgo y violencia de diversos tipos, sino que se generalizan los estereotipos de género más penosos: el hombre tiene deseo sexual permanente y la mujer se dedica a dar satisfacción a ese deseo"27. Y lógicamente, este paradigma da lugar a la relación entre consumo de pornografía y agresiones violentas contra la mujer ${ }^{28}$.

Lo cierto es que Internet ha amplificado de tal manera el consumo de pornografía que puede hablarse sin exagerar de una sociedad pornificada. Internet es el gran almacén

\footnotetext{
${ }^{24}$ op. cit. p. 46

${ }^{25}$ De Miguel, Ana (2019), op. cit. 142.

${ }^{26}$ Ballester, Ll.; Orte, C. y Pozo, R. (2019). Nueva pornografía y cambios en las relaciones interpersonales de adolescentes y jóvenes en Ballester, Ll.; Orte, C. y Pozo, R. (Coords) (2019). Vulnerabilidad y resistencia: experiencias investigadoras en comercio sexual y prostitución. UIB. Col.lecció Treballs feministes (16).

${ }^{27}$ Ballester, Ll.; Orte, C. y Pozo, R. (2019) op. cit. 264.

${ }^{28}$ Los investigadores se apoyan en un estudio de 2015 con resultados bastante concluyentes: Wright, P.J.; Tokunaga, R.S. y Kraus, A. (2015). A meta-analysis of pornography consumption and actual acts of sexual agression in general population studies. Journal of Communication, 66,(1). Cfr. Igualmente, Gallego Rodríguez, Claudia y Fernández González. Liria (2019). ¿Se relaciona el consumo de pornografía con la violencia hacia la pareja? El papel moderador de las actitudes hacia la mujer y la violencia. Psicología Conductual. 27 (3), 431-454.
} 
de contenidos pornográficos y es en cierta manera el gran protagonista de la red. Una de cada siete búsquedas en la web está relacionada con pornografía (15\%). El sitio web de pornografía más visitado del mundo, Pornhub, es casi tan popular como Netflix y Linkedin. ${ }^{29} \mathrm{Y}$ aunque el modelo de negocio gratuito parece estar llegando a su fin con la irrupción de SnapChat, lo cierto es que la industria tiene una gran capacidad de adaptación e innovación. La industria del porno mueve miles de millones de euros cada año y ese gran poder económico dificulta la adopción de cualquier medida restrictiva.

\section{Los instrumentos del ordenamiento legal}

3.1. La clasificación y acceso de contenidos pornográficos. Ha sido tradicional en el Derecho administrativo la intervención sobre los contenidos pornográficos a través de la clasificación y los límites al acceso. Así, la Ley 55/2007, del Cine contempla mecanismos para la clasificación de los contenidos. (arts. 8 y 9). Para las películas llamadas (X) es decir que contengan escenas de sexo explícito o contenidos para adultos, se impone un circuito especial de exhibición. El organismo responsable de efectuar esta clasificación es el Instituto de Cinematografía y Artes Audiovisuales (ICAA). Lo mismo puede decirse respecto de los contenidos que se programen en televisiones. La Ley de Comunicación Audiovisual (Ley 7/2010, de 31 de marzo), contempla en su art. 7.2. que "Está prohibida la emisión de contenidos audiovisuales que puedan perjudicar seriamente el desarrollo físico, mental o moral de los menores, y, en particular, la de aquellos programas que incluyan escenas de pornografía, maltrato, violencia de género o violencia gratuita." A diferencia de la gran pantalla, los contenidos televisivos cuentan con una prohibición expresa en determinadas franjas horarias (horario especialmente protegido). Pero también a diferencia del cine, no hay propiamente una autoridad administrativa encargada de la clasificación y su cumplimiento sino que se recurre a la autorregulación. ${ }^{30}$ Es Autocontrol, un organismo formado por las propias cadenas, quien se encarga por velar por el cumplimiento de la norma y recibir y tramitar, en su caso, denuncias por infracciones. Junto con lo anterior, se ha extendido también un sistema de clasificación para los videojuegos que empezó a exigirse a partir de 2001 por parte de los editores y distribuidores de software de entretenimiento.

El sistema de clasificación no deja de ser un sistema de intervención administrativa previa donde se analizan los contenidos con carácter previo a su distribución y exhibición. Cada ordenamiento podrá imponer una mayor o menor restricción según la política gubernamental que exista. No se trata de una censura sino de un mero mecanismo informativo. No se prohíben contenidos sino que, o bien se determina un circuito especial de exhibición o bien se imponen unas determinadas franjas horarias para la protección de la infancia y los menores.

\footnotetext{
${ }^{29}$ En 2017, en todo el mundo se realizaron un total de 28.500 millones de visitas a Pornhub y un registro de 4.052 .543 videos pornográficos cargados. https://www.forbes.com.mx/2017-el-ano-que-supero-las-cifras-y-las-busquedas-enla-industria-porno/

${ }^{30}$ Igual que hace el articulo 10.1. letra c) del Anteproyecto de Ley de garantia integral de la libertad sexual de la mujer. Cfr. Nota al pie 1."
} 
Este sistema aparece hoy como obsoleto, al igual que es obsoleto el canal de distribución físico de los contenidos pornográficos. La llamada nueva pornografía utiliza casi exclusivamente la distribución por Internet de manera que las restricciones se burlan con total facilidad. Cabe preguntarse, sin embargo, si la Ley permite la imposición de restricciones. Si se acude a la Ley 34/2002, de 11 de julio, de Servicios de la Sociedad de la Información, la cuestión queda fuertemente diluida en un mero código de conducta y la prohibición de envío de comunicaciones comerciales que inciten al juego.

Destaca poderosamente la incapacidad del legislador para trasladar un sistema de intervención administrativa mínima sobre los contenidos y sobre su acceso cuando éstos se producen de forma abrumadora por Internet. Seguimos pues regulando los canales tradicionales mientras delante de nuestros ojos prolifera la libre distribución por Internet. El modo de acceso actual -más si cabe con tecnología 5G de telecomunicaciones- es el teléfono móvil del que disponen un alto porcentaje de menores de 14 años ${ }^{31}$. Es cierto que existen mecanismos de limitación como el control parental o como la acreditación de la mayoría de edad para el acceso cuya burla resulta, sin embargo, tan fácil como extendida. Aunque el Derecho siempre vaya por detrás de la realidad, parecería exigible una mayor determinación normativa, máxime con lo que diremos en el apartado siguiente.

Si se acude al Derecho comparado resulta que algunos países empiezan ya a tomar cierta conciencia de la escandalosa situación de anomía (ausencia de cualquier tipo de regulación). En UK se debatió en el Parlamento en 2017 una modificación de la Ley de Economía Digital con la finalidad de regular el consumo de contenidos pornográficos onli$n^{32}$. Según la propuesta -que al final no prosperó- los británicos que quisieran consumir contenidos para adultos deberían adquirir previamente un pase para acceder a este tipo de contenidos en los puestos de periódicos locales tras haber acreditado efectivamente su mayoría de edad. Otras de las propuestas que se barajaban para controlar el acceso de menores, era la obligatoriedad de suministrar los datos de una tarjeta de crédito de manera previa a entrar en las páginas clasificadas. Ello sin embargo planteaba problemas tanto de protección de datos personales como de potencial uso fraudulento de esos datos sensibles. Las iniciativas contaban con la participación del Britsh Board for Film Classification (BBFC) que veía con preocupación la distancia que antes hemos expresado entre sistema de clasificación "tradicional" pensado para el soporte físico y la total libertad que impera en Internet. El sistema de código de acceso adquirible en puntos de distribución comercial (quioscos) hubiera permitido restringir el acceso a ciertos contenidos puesto que solo mediante la acreditación con un documento oficial expresivo de la edad y con el pago de una cantidad (10 libras esterlinas) se permitiría el acceso a contenidos clasificados. El sistema no es infalible puesto que, una vez adquirido, es anónimo y se puede transferir pero supone un primer esfuerzo por intervenir el libre y total acceso.

\footnotetext{
${ }^{31}$ Instituto Nacional de Estadística. Encuesta sobre Equipamiento y Uso de Tecnologías de Información y Comunicación en los Hogares. Año 2019. Nota de prensa disponible en https://www.ine.es/prensa/tich_2019.pdf

${ }^{32}$ La tramitación completa puede consultarse en https://services.parliament.uk/bills/2016-17/digitaleconomy/ documents.html
} 
Más recientemente, la Asamblea Nacional francesa ha aprobado en 2020 una norma ${ }^{33}$ que concede al Conseil Supérieur de l'Audiovisuel (CSA) francés la potestad de bloquear las páginas que no respeten la obligación de que el usuario acredite en la propia página su mayoría de edad. La Ley no indica exactamente cómo hacerlo y será seguramente el desarrollo de la misma la que concretará ese crucial aspecto. Entre los métodos que se barajan como posibles están la tarjeta de crédito -que es el sistema que falló en el Reino Unido- así como la acreditación mediante FranceConnect, una herramienta digital creada por el estado francés y equivalente al sistema 'Cl@ve' español. El CSA podrá rastrear si una web con contenido pornográfico no está efectivamente comprobando la edad del usuario que quiere acceder. En ese caso, tendrá potestad para intimarle a hacerlo y a establecer un sistema de control efectivo. Si no se atiende al requerimiento el CSA cuenta con la potestad de solicitar una orden para que los operadores de telecomunicaciones de Francia bloqueen el acceso a la web.

Estas y otras experiencias demuestran que se empieza a adquirir consciencia de la dimensión del problema del libre acceso y consumo de contenidos pornográficos en Internet, con la especial preocupación de la protección de la infancia y la juventud. Parece claro que el sistema de clasificación administrativa debe ir acompañado de una restricción de acceso que no sea puramente aparente. En este aspecto, y visto que no resulta efectiva la mera autorregulación ni la apelación a los filtros parentales, el Derecho y la regulación tienen un papel inexcusable del que no deben rehuir por la existencia de dificultades técnicas.

\subsection{Derecho penal}

La producción, distribución y consumo de pornografía (excepto la infantil), no constituye un ilícito penal. La escalada del porno violento parece ser el traslado a la sexualidad de nuestra sociedad violenta. Pero también un mecanismo de adicción:

no hace falta más que mirar cómo la violencia ha adoptado el lenguaje de la pornografía para expresar sus signos más escandalosos. (...) En la búsqueda del aún más, el porno ha ido acercando sus propuestas al dolor (grabaciones de asesinatos, violaciones reales o simuladas y torturas. No en vano, la denigración de la mujer transformada en un mero cuerpo impersonal es una forma de violencia) ${ }^{34}$.

Un ejemplo de lo anterior puede verse en la exhibición en el festival de cine de Sitges en 2010 de la cinta A Serbian Film, opera prima del director Srdjan Spasojevic. El largometraje contiene escenas tan perturbadoras de pornografía violenta, snuff o gore como la violación de un recién nacido todavía unido por el cordón umbilical a la madre o el arranque de las piezas dentales de una mujer para seguidamente obligarle a realizar una felación. Pese a la posición de la fiscalía, el Juzgado de Primera Instancia nº8 de Vilanova

\footnotetext{
${ }^{33}$ LOI n ${ }^{\circ}$ 2020-936 du 30 juillet 2020 visant à protéger les victimes de violences conjugales. Disponible en https:// www.legifrance.gouv.fr/jorf/id/JORFTEXT000042176652?r=P7ps2iPojw

${ }^{34}$ Iglesias, A. y Zein, M. (2018). 46.
} 
i la Geltrú archivó la querella. La exhibición de la misma cinta se paralizó judicialmente para la Semana de Cine Fantástico de San Sebastián, lo que no impidió que se otorgara a la obra el premio especial del público del mencionado certamen.

Más allá del caso concreto, lo cierto es que la nueva pornografía se caracteriza no solo por su fácil acceso sino también contenido cada vez más extremo en una especie de carrera incrementalista. No se trata ya solo de imágenes de sexo explícito que puedan provocar la excitación del consumidor sino de contenidos altamente perturbadores cuya sola descripción incomoda.

El Código Penal contempla los delitos contra la libertad e indemnidad sexual en su Título VIII, distinguiendo entre la agresión (arts. 178-180) y el abuso (arts. 181-182), según exista o menos violencia o intimidación. Para ellos se contempla una agravante específica para cuando la violencia o intimidación ejercidas revistan un carácter particularmente degradante o vejatorio. (art. 180.1. agravante primera que viene a unirse a la agravante general subjetiva del art. 22.4). Esta previsión general, lamentablemente, no se aplica para los contenidos pornográficos en la red, donde nada parece susceptible de tener límites.

Algunos contenidos - de ahí la importancia de proceder a su clasificación como anteriormente hemos defendido- pueden incurrir en apología e incluso incitación a la comisión de delitos contra la libertad sexual (por ejemplo las violaciones a mujeres).

El artículo 18 del Código Penal (LO 10/1995, de 23 de noviembre) contiene, en su redactado vigente, varias categorías jurídicas distintas:

a) La provocación. La provocación existe cuando directamente se incita por medio de la imprenta, la radiodifusión o cualquier otro medio de eficacia semejante, que facilite la publicidad, o ante una concurrencia de personas, a la perpetración de un delito. (art. 18.1). Si a la provocación hubiese seguido la perpetración del delito, se castigará como inducción. (art. 18.2, párrafo $2^{\circ}$ )

b) La apología, en cambio, a los efectos de este Código penal, se define como la exposición, ante una concurrencia de personas o por cualquier medio de difusión, de ideas o doctrinas que ensalcen el crimen o enaltezcan a su autor. La apología sólo será delictiva como forma de provocación y si por su naturaleza y circunstancias constituye una incitación directa a cometer un delito.

Tanto la provocación como la apología solo se contemplan para determinados delitos (numerus clausus): homicidio y asesinato, lesiones, detenciones ilegales y secuestros, exhibicionismo y provocación sexual, robo, extorsión, estafa o apropiación indebida, receptación y otras conductas afines, cultivo y tráfico de drogas, rebelión militar, delitos contra la corona, asociación ilícita, sedición, atentados, terrorismo, y genocidio. Nótese como -sorprendentemente- los únicos delitos contra la libertad e indemnidad sexual por cuya gravedad el legislador opta por castigar su apología son los de exhibicionismo y provocación sexual (arts. 185-186).

En 2018 dentro del coloquio 'Defensa de los Estados democráticos en el ciberespacio' y en el marco de los cursos de verano de la Universidad Internacional Menéndez Pelayo 
(UIMP), el juez de la Audiencia Nacional Eloy Velasco consideraba tremendamente necesario tipificar en el código penal delitos específicos como el de la apología de la violación o la pornografía infantil formulada a través de Internet. ${ }^{35}$ Esta es, sin embargo, una posición minoritaria dentro de la doctrina jurisprudencial por cuya extensión debe abogarse.

También podemos legítimamente preguntarnos si determinados contenidos pornográficos en la red, por la humillación y vejación de las mujeres constituye, per se, un delito de incitación a la violencia de género. El ordenamiento español no permite el discurso del odio lo que incluye el mensaje de odio al género femenino. Así, el art. 510.1. b) del Código Penal establece, en su reforma acometida por la Ley Orgánica 1/2015, de 30 de abril que son punibles -de forma agravada si se utiliza "Internet o uso de tecnologías de la información, de modo que sea accesible a un elevado número de personas"- la producción, elaboración, posesión con la finalidad de distribuir, facilitación a terceras personas del acceso, distribución, difusión o venta de "escritos o cualquier otra clase de material o soportes" que inciten directa o indirectamente al odio, hostilidad, discriminación o violencia contra un grupo, una parte del mismo o contra una persona determinada por razón de su pertenencia a aquél, por motivos racistas, antisemitas u otros referentes a la ideología, religión o creencias, situación familiar, la pertenencia de sus miembros a una etnia, raza o nación, su origen nacional, su sexo, orientación o identidad sexual, por razones de género, enfermedad o discapacidad ${ }^{36}$.

Por lo tanto, parece que el Derecho penal dispondría de un tipo específicamente pensado para la difusión de los contenidos pornográficos humillantes, vejatorios o violentos contra las mujeres. No haría falta siquiera recurrir a la construcción de las distintas categorías del art. 18 (provocación o inducción) sino que se contemplaría como un tipo delictivo de la parte especial. En palabras de Gómez Martín,

a pesar de la no exigencia en el tipo básico del precepto de la idoneidad objetiva de la conducta para alterar la paz pública para crear un grave sentimiento de inseguridad o temor entre los integrantes del grupo, parece razonable exigir, no obstante, al menos, que se trate de un comportamiento mínimamente adecuado para alterar de algún modo la seguridad colectiva o el honor de la mujer como colectivo ${ }^{37}$.

Y si correlacionamos lo anterior con las estadísticas judiciales, la cuestión se revela como meridianamente clara.

Una reflexión final: ante miles de páginas libremente accesibles donde se muestran contenidos de violaciones, vejaciones y graves humillaciones contra mujeres ¿debe el Derecho penal y la política criminal permanecer impasible? ¿no constituyen estos contenidos la semilla de la posterior emulación real de los delitos?. No se trata de una visión mo-

\footnotetext{
${ }^{35}$ Rebolledo, M.G. (10 de julio de 2018). El juez Eloy Velasco propone tipificar la apología de la violación como delito informático. El Mundo. https://www.elmundo.es/espana/2018/07/10/5b44999be2704e82938b45a0.html

${ }^{36}$ Un análisis más detallado puede verse en la Circular 7/2019, de 14 de mayo, de la Fiscalía General del Estado, sobre pautas para interpretar los delitos de odio tipificados en el artículo 510 del Código Penal. Disponible en https:// www.boe.es/boe/dias/2019/05/24/pdfs/BOE-A-2019-7771.pdf

${ }^{37}$ Gómez Martín, V. (2016).
} 
ralista que propugne una censura previa a los contenidos (del tipo ocultar con estrellitas los pezones o pixelar los primeros planos de órganos genitales). Se trata de limitar una carrera desenfrenada hacia los contenidos que constituyen una denigración de la mujer y su cuerpo. Ciertamente, la pornografía lo es en tanto que cumpla la finalidad de excitación sexual del receptor. ¿No debería el visionado de una mujer golpeada o vejada desatar la turbación y repulsión de quien lo contempla en vez de excitación y placer? Pero mientras no se llegue a ese mínimo de dignidad, el ordenamiento jurídico no debe abdicar de la utilización de determinados mecanismos limitativos.

\subsection{La ilegalización de páginas web con contenidos violentos y/o denigrantes}

Internet ha cumplido ya 50 años. En un primer momento -bastante ingenuo- la libertad de Internet se contemplaba como un avance frente a la intervención de gobiernos y la obligatoria intermediación de conglomerados de comunicación. La herramienta aparecía como un espacio de libertad e ilimitada interacción social. Muy rápidamente, sin embargo, desaparece esta venda buenista y nos damos cuenta de que la red tiene también un enorme potencial dañino. En la medida en que sean utilizados medios informáticos para difundir las imágenes que ensalzan el delito, la apología de delitos se convierte en delito informático, y en este sentido, son cada vez más numerosas las intervenciones frente a páginas Web que promocionan conductas delictivas cuya tipificación aquí planteamos.

La autorregulación de las redes o la ausencia de cualquier tipo de regulación pública pone de manifiesto sus insuficiencias. Así, por ejemplo, se consigue avanzar muy lentamente en la responsabilidad de los proveedores de Internet por los contenidos que alojan. Ello es clave en la persecución del tráfico de drogas, los delitos de odio o la pornografía infantil. Al no considerar los proveedores como editores, se creaba un sistema de puerto seguro que se ampara en varias legislaciones norteamericanas y europeas, en especial en lo relativo a las vulneraciones de los derechos de propiedad intelectual de las creaciones musicales. Esta falsa idea de neutralidad, sin embargo se cuestiona en el caso Payam Tamiz c. Google de $2013^{38}$ donde el tribunal inglés considera que Google, una vez es notificado por el perjudicado del contenido difamatorio de la página, puede ser considerado como un "editor por aquiescencia". Si se traslada a nuestro caso, una vez identificado y denunciado un contenido pornográfico penalmente relevante ${ }^{39}$, el proveedor de Internet o el alojador de la página puede ser responsable.

La tensión entre derecho a la intimidad del usuario y derecho a la protección de sus datos se manifiesta también en la reciente STEDH Benedik v. Eslovenia. ${ }^{40}$ En el caso, se vulneraría el derecho individual por el acceso policial a los datos sobre atribución de IP di-

\footnotetext{
${ }^{38}$ Tamiz v Google Inc [2013] England and Wales Court of Appeal Civ 68 de 14 de febrero de 2013. Disponible en http://www.bailii.org/ew/cases/EWCA/Civ/2013/68.html

${ }^{39}$ De ahí precisamente la utilidad de la intervención administrativa clasificatoria que debería permitir determinar qué contenidos resultan contrarios a la legalidad.

${ }^{40}$ STEDHde24deabrilde2018.Disponibleenhttps://hudoc.echr.coe.int/fre\#\{\%22itemid\%22:[\%22001-182455\%22]\}
} 
námicas (revelar la conexión entre el dato y el usuario) si ello se produce sin la preceptiva intervención judicial. Al igual que sucede con la inviolabilidad de domicilio o el secreto de las comunicaciones, puede/debe establecerse un sistema de salvaguarda de los derechos por parte de un juez de garantías.

Parece absurdo poder englobar dentro de la libertad de expresión la difusión de contenidos ilegales, pues en nombre de la libertad de expresión no puede ampararse lesiones de otros de bienes jurídicos superiores ${ }^{41}$. Cuando la libertad de expresión se convierte en un instrumento al servicio de los que atentan contra la vida y la libertad sexual de la mujer, debería actuar el Derecho y -con todas las garantías que se precisen- excepcionar el principio de libertad.

La ley 2/2011, de 4 de marzo, de Economía Sostenible contempla ya un modelo de intervención para el cierre de páginas web que atenten contra los derechos de propiedad intelectual. El sistema administrativo resulta bastante débil pues depende de que el servidor esté situado en territorio español. De nuevo, una medida insuficiente para el mundo digital que, sin embargo, no es suficiente excusa para no abordar una regulación más estricta. La cuestión parece algo más efectiva en lo que refiere a los contenidos relativos a la pornografía infantil, cuyo modelo podría extenderse.

\section{Conclusiones}

El resultado de nuestro análisis revela dos cuestiones que podemos considerar como casi-ontológicas: En primer lugar, el Derecho, como sistema de ordenación social refleja los valores de la sociedad en la que se aplica. Hay una retroalimentación entre sociedad y Derecho de manera que un determinado ordenamiento legal expresa cómo es esa sociedad y su escala de valores y a la inversa. En nuestro caso, la poca incisividad del Derecho en la restricción de las manifestaciones de violencia, humillación o vejación de las mujeres a través de la pornografía muestra una preocupante tolerancia. En segundo lugar, el Derecho siempre va por detrás de la realidad social. Se recurre al Derecho cuando la realidad ha desbordado ciertos marcos de convivencia. No se utiliza normalmente el Derecho como forma de prevenir o anticipar. Así, en nuestro caso, se manifiesta doblemente: las medidas legales de represión de la violencia contra las mujeres no adoptan ni un enfoque preventivo ni transformador.

A lo anterior, debe unirse, en segundo lugar, una especie de torpeza tecnológica del operador jurídico. Desde el legislador hasta el juez, pasando por la propia Administración pública se ven superados por la capacidad tecnológica de aquello que quiere limitar. Parece que el mundo digital -que el final no es más que una creación humana- queda al margen de su alcance: problemas de jurisdicción internacional; sesgos decisionales debido a algoritmos, o falta de funcionarios debidamente formados. Todo se confabula para cierta parálisis normativa.

\footnotetext{
${ }^{41}$ Cfr. en este sentido la limitación del legislador en el art. 10.1. del Anteproyecto de Ley de garantia integral de la libertad sexual de la mujer. (Nota al pie 1).
} 
Como hemos expresado al inicio, los datos objetivos sobre criminalidad que sufren las mujeres (tanto violencia sexual como otros tipos de violencias) no solo no mejoran pese a los esfuerzos sino que parecen empeorar. Y empeoran tanto cuantitativamente como también cualitativamente (en el sentido que incorporan a las generaciones jóvenes al paradigma de desigualdad y maltrato por razón de género). Probablemente la cosificación, hipersexualización y pornificación de la sociedad constituyen indicios de este empeoramiento cualitativo.

No hacen falta más normas sino un mejor diseño de las políticas públicas sectoriales. De hecho, como síntesis de las precedentes páginas, valdría la pena profundizar algunos márgenes de mejora del ordenamiento vigente que expresamos en forma de propuestas: (i) contextualizar la violencia sexual como una forma de violencia de género, ya que ésta afecta a las mujeres de forma desproporcionadamente alta; (ii) clasificar los contenidos pornográficos identificando aquellos que contengan representaciones violentas, denigrantes, humillantes o vejatorias contra las mujeres y establecer mecanismos de control previo de acceso a determinados contenidos clasificados; (iii) aplicar las figuras delictivas de la inducción o la apología criminal a los contenidos que supongan representaciones violentas, denigrantes, humillantes o vejatorias contra las mujeres. Para ello se debe incluir en la enumeración del art. $18 \mathrm{CP}$ los delitos contra la libertad e indemnidad sexual; (iv) utilizar la tipificación autónoma del artículo 510 CP como instrumento de persecución de contenidos que inciten directa o indirectamente al odio, hostilidad, discriminación o violencia contra las mujeres, por suponer una potencial puesta en peligro de su seguridad colectiva; $y$, finalmente, (v) obligar a los proveedores de Internet a retirar los contenidos que puedan considerarse ilegales por incitar al odio contra las mujeres así como corresponsabilizar a las plataformas de contenidos mediante la aplicación de la figura del "editor por aquiescencia".

Ninguna de estas propuestas legales implica una solución ni fácil ni inmediata. Pero parecería exigible explorar algunas de las posibilidades que ofrecen. El problema es de tal dimensión que no puede seguir insistiéndose solamente en las normas represivas de las conductas de los agresores sino anticiparse para que éstos no encuentren modelos que, por accesibles y difundidos, terminan normalizando las conductas delictivas.

\section{Bibliografía}

BALLESTER, Ll.; ORTE, C. y POZO, R. (2019). Nueva pornografía y cambios en las relaciones interpersonales de adolescentes y jóvenes. En BALLESTER, Ll.; ORTE, C. y POZO, R. (Coords). (2019). Vulnerabilidad y resistencia: experiencias investigadoras en comercio sexual y prostitución. UIB. Col.lecció Treballs feministes (16).

BUENO DE MATA, F. (2015). La apología de la violencia de género en internet: cuestiones procesales y problemas prácticos. La Ley Penal: revista de derecho penal, procesal y penitenciario, 114.

COBO, Rosa. (2020). La pornografía. El placer del poder. Ediciones B. 
CUERDA ARNAU, M.L. (2010) Los delitos contra la libertad sexual de la mujer como tipos de violència de genero. Consideraciones críticas. Revista General de Derecho Penal, 13.

DE LA MATA BARRANCO, J.N. (2017). Delitos de incitación al odio, hostilidad, discriminación y violencia en DE LA CUESTA ARZAMENDI,J.L.; DE LA MATA BARRANCO, N.J. y BLANCO CORDERO, I (Coords).(2017). Adaptación del derecho penal español a la política criminal de la Unión Europea. 393-400.

DE MIGUEL, A. (2019). Neoliberalismo sexual. El mito de la libre elección. Cátedra-Universitat de València. $12^{\mathrm{a}}$ ed.

FERNÁNDEZ ESTRADA, M. (2011). La mercantilización de los cuerpos. ¿Paz social entre los hombres, guerra no declarada a las mujeres. Investigaciones Feministas 2, 259-281.

GALLEGO RODRÍGUEZ, C. y FERNÁNDEZ GONZÁLEZ, L. (2019). ¿Se relaciona el consumo de pornografía con la violencia hacia la pareja? El papel moderador de las actitudes hacia la mujer y la violencia. Psicologia Conductual. 27 (3), 431-454.

GOMEZ MARTÍN, V. (2016). Incitación al odio y género. Algunas reflexiones sobre el nuevo art. 510 CP y su aplicabilidad al discurso sexista. Revista Electrónica de Ciencia Penal y Criminología, 18.

GONZÁLEZ PÉREZ, J. (1996). La pornografía en el Tribunal Constitucional. Revista Española de Derecho Administrativo, 9, 467-475.

IGLESIAS, A. y ZEIN, M. (2018). Lo que esconde el agujero. El porno en tiempos obscenos. Los Libros de la Catarata.

MUÑOZ CUESTA, F.J. (2014). Apología o provocación al delito a través de las redes sociales. Actualidad Jurídica Aranzadi, 886.

PAASONEN, S. (2016). Pornification and the Mainstreaming of Sex. Oxford Research Encyclopedias, Criminology and Criminal Justice. https://doi.org/10.1093/acrefore/9780190264079.013.159

PULEO, A. H. (2015). Ese oscuro objeto del deseo: cuerpo y violencia. Investigaciones Feministas, 6, 122-138.

REBOLLO VARGAS, R. (1997). La provocación y la apología en el nuevo Código penal: la exteriorización de la voluntad delictiva. Tirant lo Blanch.

RODRIGUEZ LAINZ, J.L. (2018). El acceso policial a información sobre atribución de IP dinámicas. Comentario a la STEDH del caso Benedik v. Eslovenia. Diario La Ley no 9241.

RODRÍGUEZ RUIZ, B. (ed.). (2019). Autonomía, género y derecho: Debates en torno al cuerpo de las mujeres. Tirant lo Blanch.

VELASCO NUÑEZ, E. (2007). Eliminación de contenidos ilícitos y clausura de páginas web en Internet (medidas de restricción de servicios informáticos). Cuadernos de Derecho Judicial, 2, (Ejemplar dedicado a: Los nuevos medios de investigación en el proceso penal. Especial referencia a la tecnovigilancia), 77-124.

UBIETO OLIVAN, A. (2018). La violencia sexual como violencia de género: una perspectiva desde el derecho internacional de los derechos humanos. Femeris, 3 (2), 165-170.

USTARAN. E. (1997). La pornografía en Internet: la respuesta legal. La Ley: Revista jurídica española de doctrina, jurisprudencia y bibliografía. 1, 2130-2132. 